\title{
Da formação do professor aos porquês dos clássicos no ensino da arte: tudo pode ser mais bonito
}

About teachers' formation and the role of classics in art classes: beauty can be everywhere

Entre la formation des enseignants d'art et le rôle des classiques : tout peut être plus beau. 


\title{
Resumo
}

Este artigo versa sobre o espaço do clássico no ensino da Arte, considerando a complexidade desse conceito que foi, ora referência central, ora território a ser evitado, nas diversas orientações para o ensino da Arte. Objetiva-se colocar face-a-face distintas concepções de abordagem dos clássicos nos processos de didatização da Arte, uma problemática central no âmbito das investigações sobre a formação de professores de arte no Observatório da Formação de Professores no âmbito do Ensino de Arte (OFPEA/BRARG). Para a construção da argumentação, a orientação metodológica adotada foi a pesquisa bibliográfica a partir de referenciais canônicos do ensino da Arte, também conhecidos como "clássicos" e de escritos atuais. Busca-se jogar luz sobre alguns critérios que têm dado corpo ao conceito de clássico assimilado pelos professores de arte e que marcam indelevelmente determinadas pinturas, músicas, romances, obras da dramaturgia, particularmente o caráter de permanência e a resistência dos clássicos aos embates do tempo (SAVIANI, 2013); que se impõem como inesquecíveis, trazendo marcas que atravessam os tempos e culturas (CALVINO, 2007). A reflexão conduz para a compreensão dos equívocos em rechaçar sumariamente os clássicos no Ensino da Arte, sob pena de negar aos estudantes elementos essenciais da relação que podemos estabelecer com a Arte.

Palavras-chave: Ensino da Arte. Formação de professores. Clássicos.

\begin{abstract}
This paper aims to discuss the idea of "classics" in Art teaching, from the complex perspective that put this concept either as the core of the educational processes, or either as a to-be-avoided conception. The objective is to put face-to-face different conceptions of the use of "classics" in the educational processes of Art, a main issue in the researches related to Art teachers' formation that are conducted in the Observatório da Formação de Professores no âmbito do Ensino de Arte (OFPEA/BRARG). Bibliographic research was the chosen methodological path, going over both traditional and contemporary Art teaching authors. The idea is to better understand the criteria that define what undoubtedly is considered "Classic", as paintings, compositions, romances, dramas, and how that conception is assumed by Art teachers. In particular it is intended to understand what defines the stability and resistance of certain Art works as "classics" (SAVIANI, 2013); or what defines art works as unforgettable through aspects that pass-through times and cultures (CALVINO, 2007).
\end{abstract}

1 Doutora em História, professora aposentada da UFPR. CV: http://lattes.cnpq.br/7613097165877094 ORCID http://orcid.org/0000-0002-6928-9274 E-mail: consuelo.ufpragmail.com

2 Doutor em Educação, professor da UFPR. CV: http://lattes.cnpq.br/7121843222449377 ORCID http://orcid. org/0000-0003-0485-8322 E-mail: guilhermeromanelli@ufpr.br 
The results intend to highlight the mistakes on summarily repel the "classics" in Art teaching, with the damage of deny to the students the essential relations that they could build with Art through the "classics".

Keywords: Art teaching. Teachers' formation. Classics.

\section{Resumé}

Cet article propose une discussion à propos du rôle des classiques dans l'enseignement de l'Art, à partir de la complexité de ce thème, soit, à la fois une référence centrale, ou soit comme une conception à être évité dans l'enseignement de l'Art. L'objectif est de confronter différentes conceptions de l'étude des classiques à l'école, ce qui est un des thèmes principaux des recherches à propos de la formation d'enseignements d'art dans Observatório da Formação de Professores no âmbito do Ensino de Arte (OFPEA/ $B R A R G)$. Pour cette argumentation la méthodologie choisie est la recherche bibliographique à partir des ouvrages canoniques de l'enseignement de l'art aussi bien que des écrits d'auteurs actuels. L'idée est de mieux comprendre les critères utilisés pour classer certaines peintures, compositions, romans et pièces de théâtre comme classiques, ainsi que leur statut de permanence et the résistance à travers le temps (SAVIANI, 2013); ou ce qui définit ces œuvres comme inoubliables et qui ont des marques qui leur permettent de traverser les temps et les cultures (CALVINO, 2007). Il est aussi un objectif de comprendre comme ces conceptions sont assimilées par les enseignements. Les conclusions permettent the comprendre les dangers d'éviter sommairement les classiques de l'enseignement de l'art, sous peine de nier aux étudiants des éléments essentiels de la relations qu'ils peuvent établir avec l'art.

Mots-clefs: Enseignement de l'Art. Formation d'enseignements. Les classiques. 


\section{Introdução}

Nos últimos anos alicerça-se um debate em torno do clássico na escola, que ora afirma ora, com igual força, nega-o veementemente nas aulas de arte. Essa problemática suscita cada vez maior interesse dos professores, pesquisadores, artistas do Observatório da Formação de Professores no âmbito do Ensino de Arte (OFPEA/ $B R A R G)$, enriquecendo também o debate com pesquisadores e professores de outros campos e grupos de pesquisa. Baseando-nos no paradoxo, acima destacado, ainda não plenamente debatido, o objetivo deste trabalho é, primeiramente, compreender o que marca indelevelmente determinadas pinturas, músicas, romances, obras da dramaturgia etc. como clássicos das Artes Visuais ou do universo da Dança, da Música, do Teatro; segundo, busca-se jogar luz sobre o conteúdo que tem dado corpo ao conceito de clássico assimilado pelos professores de arte, partindo do conceito de clássico como "aquilo que tem caráter permanente, isto é, o que resistiu ao tempo" (SAVIANI, 2013, p. 17); em terceiro lugar, objetiva-se problematizar quais critérios satisfazem as exigências claramente demonstradas por Saviani $(2013,2009)$ e Calvino (2007, p. 11): "um clássico é um livro que nunca terminou de dizer aquilo que tinha para dizer". Por fim, e como consequência do objetivo posto anteriormente, quais as formas de transmissão-assimilação desses saberes extraídos da riqueza artística produzida pelo conjunto da humanidade, sem transformá-los em saber gratuito descolado das maneiras de agir, sentir, pensar, que constituem a cultura?

A abordagem metodológica para a escrita deste trabalho se fundamenta em pesquisa bibliográfica nos campos da estética, da educação, do ensino da arte, além de outras áreas do conhecimento que trazem referenciais teóricos necessários à problematização deste tema, a exemplo de alguns excertos sobre a história do ensino da arte, século XIX. Os teóricos aqui abordados representam parte da literatura canônica sobre o tema, também conhecidos como "clássicos", assim como autores contemporâneos. Também se leva em consideração a íntima unidade entre teoria e prática na atuação dos dois autores com algumas décadas de experiência tanto no campo artístico quanto no campo educacional, em particular na formação de professores de arte. As análises e reflexões apresentadas neste texto têm sido objeto de debate no Observatório da Formação de Professores no âmbito do Ensino de Arte (OFPEA/BRARG) e se propõem sobretudo contribuir para o acesso dos professores aos conhecimentos artísticos clássicos, como antídoto contra a ideologia de que a "a arte só pode ser duas coisas: ornamento e mercadoria" (LEMINSKI, 2014, p. 25).

\section{Clássico: a construção de um conceito}

Voltando ao objeto de nossa análise no presente estudo, inicialmente destacamos Saviani $(2009,2013)$ e Calvino (2007), entre tantos outros autores que têm largamente explanado sobre o conceito de clássico. Para Saviani (2013, p. 13), a noção de clássico "constituir-se num critério útil para a seleção dos conteúdos do trabalho 
pedagógico". Destaca-se Saviani porque este autor contribui sobremaneira para a seleção dos conhecimentos científicos, filosóficos e artísticos do trabalho educativo ao esclarecer que o clássico abrange não só um amplo e rico conjunto de criações artísticas, mas também filosóficas e científicas. A guisa de exemplo destaca Kant e Hegel, na filosofia; Vitor Hugo, autor de "Os Miseráveis", romance publicado em 1862, um clássico da literatura francesa; Guimarães Rosa, um dos grandes escritores da literatura brasileira etc. Este autor argumenta ainda: "O clássico não se confunde com o tradicional e também não se opõe, necessariamente, ao moderno e muito menos ao atual. O clássico é aquilo que se firmou como fundamental, como essencial" (SAVIANI, 2013, p. 13).

Calvino, por sua vez, esclarece o que determina a origem de um clássico, ao afirmar: "Os clássicos são aqueles livros que chegam até nós trazendo consigo as marcas das leituras que precederam a nossa e atrás de si os traços que deixaram nas culturas que atravessaram ou mais simplesmente na linguagem ou nos costumes". (CALVINO, 2007, p. 10-11).

Como é inerente a todo esforço de conceituação, as classificações e categorizações são essenciais pois ajudam-nos a cercar o objeto estudado. Não podemos esquecer que a existência humana "apresenta um lado subjetivo e um lado objetivo, intimamente conexionados numa unidade dialética" (SAVIANI, 2009, p. 18). Assim, no esforço de compreensão dos sentidos que imprimem uma marca indelével em determinadas criações consideradas clássicas, assumimos uma posição que exige certa objetividade, porém, objetividade não significa neutralidade, significa que nossas "escolhas" são interessadas por que mediadas pelas experiências em conexão íntima com nossas referências teóricas.

A exemplo do termo erudição, segundo Saviani (2009, p. XVII), não raro confundido com "mera dissecação de discursos", como "saber gratuito descolado das maneiras de agir, sentir, pensar que constituem a cultura", é fundamental resgatar os sentidos que levam a valorização ou a negação do clássico na escola. E a compreensão dos seus sentidos predominantes se dá mediante uma análise do movimento histórico, político e cultural brasileiro em que este conceito foi se engendrando, pois, conforme premissa claramente explicitada por Marx e Engels (1993), as ideias subordinam-se à vida material dos homens e mulheres.

Os homens são os produtores de suas representações, de suas ideias, etc., mas os homens reais e ativos, tal como se acham condicionados por um determinado desenvolvimento de suas forças produtivas e pelo intercâmbio que a ele corresponde até chegar às suas formações mais amplas. A consciência jamais pode ser outra coisa do que o ser consciente, e o ser dos homens é o seu processo de vida real. (...) Não é a consciência que determina a vida, mas a vida que determina a consciência (MARX; ENGELS, 1993, p. 36-37) 
Partindo deste fundamento: a subordinação das ideias, das representações à vida material dos homens e mulheres, lançamos nosso olhar sobre o conteúdo que se foi atribuindo ao termo clássico, desde a época da transferência da sede da monarquia para o Brasil, em 1808. Ou seja, retomando as medidas implementadas à época, problematizar: o que levou o próprio D. João VI iniciar negociações para a vinda da Missão Artística Francesa, em 1816? Por que, para D. João VI, o Brasil precisava dos "socorros da estética"? O que significou a criação da Academia Imperial de Belas Artes? Por que a Academia é considerada a matriz do ensino de desenho e pintura no Brasil? Há evidências dos laços entre política a arte, no Brasil, século XIX? Por fim, qual a concepção de clássico à época (SCHLICHTA, 2006)?

Desde o desembarque da Família Real para o Brasil, em 1808, para superar a imagem de obscuridade na qual o Brasil, em razão da experiência de colônia, ainda estava mergulhado, tornou-se necessária uma transformação cultural, era preciso aformosear a cidade do Rio de Janeiro, sede do governo, torná-la digna de abrigar a corte. Por isso a fundação de algumas instituições como a Real Biblioteca e a Imprensa Régia em 1810, a inauguração do Real Teatro de São João, que permitiriam ao Brasil também respirar "ares civilizatórios". Até mesmo providenciou-se um compositor e maestro, Marcos Antônio Portugal, que assumiria as funções de mestre da Capela Real e da Real Câmara, em 1811 (MALERBA, 2000).

É na esteira dessas providências que se dá a criação da Escola Real das Ciências, Artes e Ofícios, conforme teor do decreto de 12 de agosto de 1816, com a rubrica do próprio D. João VI. O Brasil, para D. João VI, precisa dos "socorros da estética". Os "socorros da estética", à época, significaram a edificação de um Sistema de Belas Artes no Brasil, afinal era preciso "abrir nova era à arte brasileira".

Esquece-se que a criação da Academia Imperial de Belas Artes, só ocorreu em 1820, e mesmo assim, a Academia Imperial de Belas Artes, considerada a instituição-mãe do ensino de desenho e de pintura no Brasil, conhecida a partir de 1842 como Escola Nacional de Belas-Artes, em nada mudou o compromisso original que assumiu com D. João VI em 1816: lugar de uma arte nacional, de uma "estética brasileira" que privilegiava os temas nacionais (PECHMAN, 2002, p. 30). A prova cabal dos laços entre política e arte e da finalidade dessa instituição e de seus artistas é a implantação em 1826 de uma seção de Pintura Histórica, com o objetivo de

dotar de imagens a saga da constituição do estado nacional, que se pretendia dos primórdios da descoberta aos "dias gloriosos" do Império. Cumpre, pois, à pintura histórica uma função estética e também, inegavelmente, educativa. (PECHMAN, 2002, p. 36).

Nesse caso, a seção de Pintura Histórica tornou-se um lugar estratégico importante na construção em "moldes visuais" da história do Brasil, de configuração da memória e preservação da história nacional, à época, os assuntos dignos da "grande 
arte" e que mereciam a atenção dos pintores, impondo-se aos artistas uma hierarquia de gêneros na qual a Pintura Histórica mantinha a posição mais "elevada" (PECHMAN, 2002, p. 30).

Pode-se distinguir aqui uma concepção de clássico, como a "grande" arte ou "as obras maiores", dignas da posteridade. No caso do Brasil, a inspiração é a Academia de Paris, o método clássico, que mobiliza artistas, engenheiros, artesãos, construída sobre a tradição greco-romana, vigorosa nos séculos XV e XVI e fundamentada na raison e no bon sens, que substitui o ideário artístico colonial apoiado no Barroco, perceptível nas obras sacras dos artistas autodidatas do Período Colonial e do Vice-Reinado. Evidencia-se que o Neoclássico brasileiro, particularmente de Debret, está diretamente ligado aos princípios formais e éticos da pintura francesa, cuja matriz é o Classicismo. Nota-se aqui a passagem do "clássico" enquanto princípio estético que atravessa séculos (mesmo milênios) e as mais variadas culturas e sociedades, desde uma antiguidade greco-romana (frequentemente idealizada) até a cultura francesa dos séculos XVIII e XIX, desembarcando no Brasil pré-independência. Atravessar períodos e culturas é um dos elementos utilizados por diversos autores para chancelar determinada referência estética enquanto "clássica" (BARBOSA, 1997).

Apesar disso, em que pese a tentativa de imposição do padrão neoclássico francês, as dificuldades de Debret são evidentes, pois, nem de longe o Brasil encarna tal exemplaridade, conforme esclarece Naves (1997, p. 65-66):

O país era governado por um monarca fugido, que viera dar aqui por obra da invasão napoleônica. Seria difícil, mesmo esquecendo que se tratava de um rei, tornar heróica uma figura com esse perfil. Transplantada, a corte agora dispunha de um cenário mirrado onde realizar seus cerimoniais, que dessa maneira adquiriam uma rudeza em tudo contrária ao esplendor natural que deveria emanar da casa real.

Há uma luta entre a forma e o conteúdo, afinal, como dar veracidade a imitação dos modelos gregos, se não há como conciliar a temática edificante e do heroísmo e desprendimento em defesa da pátria ou da república, em geral extraída dos feitos da república romana, e a imagem do séquito que aqui se instalou? Nas circunstâncias descritas é evidente o descompasso e a inferioridade da colônia, tanto nas artes quanto nas conveniências da vida, a exemplo das comemorações pelo aniversário da rainha: "tratava-se de um dia de gala, e a classe rica da sociedade fizera o que pudera para se mostrar", contudo, era conduzida por carros abertos puxados por mulas e conduzidos por negros escravizados (NAVES, 1997, p. 66).

Conforme esclarece Carvalho (1990), para Jacques-Louis David, pintor de uma das principais obras do classicismo, O Juramento dos Horácios, de 1784,

(...) o classicismo não era apenas um estilo, uma linguagem artística. Era também uma visão do mundo clássico como um conjunto de valores sociais e po- 
líticos. Era a simplicidade, a nobreza, o espírito cívico, das antigas repúblicas; era a austeridade espartana, a dedicação até o sacrifício dos heróis romanos. O artista devia usar sua arte para difundir tais valores CARVALHO, 1990, p. 11).

Pode-se deduzir, assim, que a "grande" pintura, além de legitimar os valores e comportamentos condizentes com uma certa política da aparência, que levassem à transformação de uma terra selvagem em um espaço civilizado, de modo a despertar o Brasil de sua modorra secular, serviria para dar veracidade e legitimar qualquer regime político. Em conclusão: "É por meio do imaginário que se podem atingir não só a cabeça, mas, de modo especial, o coração, isto é, as aspirações, os medos e as esperanças de um povo. É nele que as sociedades definem suas identidades e objetivos, definem seus inimigos, organizam seu passado, presente e futuro" (CARVALHO, 1990, p. 10-11).

Não por acaso, o estabelecimento da identidade do Brasil se deu num jogo ora de admiração e aceitação da Academia Imperial de Belas Artes na construção da identidade nacional ora de desprezo e recusa à absorção de um imaginário da brasilidade "à europeia", muitas vezes réplica dos modelos do velho Mundo, que se diferencia apenas nos detalhes. Tal relação paradoxal já era um anúncio do papel que as diversas iniciativas de ensino de Arte teriam ao longo dos séculos seguintes e que ainda hoje é notada: a coexistência de argumentos teóricos, metodológicos e filosóficos que, ora repudiam o estudo dos clássicos e ora defendem seu espaço na educação.

A descrição de diversos elementos da Missão Artística Francesa do início do século XIX não tem a intenção de ser exaustiva, mas jogar luz sobre dois elementos-chave desse movimento estético-político-cultural que são essenciais para compreender o lugar do clássico na educação. O primeiro refere-se ao contato com a Arte Clássica, vista como essencial à construção de uma ideia de nação.

Poucos tinham acesso a essa cultura, em um Brasil com status de colônia. Destaca-se Manoel Dias de Oliveira (1764-1837), que introduziu em 1800 o modelo nu em pleno Brasil ainda colonial, uma prática que seria muito explorada pela Missão Francesa. Como se pode constatar na descrição de uma de suas aulas, o modelo vivo não causava nenhum estranhamento pois era tratado de modo idealizado. Segundo Babosa (1999, p. 23-24): "A figura tornava-se apenas um ponto de apoio para observação, e a imagem desenhada obedecia, não nos padrões vistos, mas nos padrões de beleza estabelecidos pelo código neoclassicista, com o qual Manuel Dias de Oliveira entrou em contato durante seus cursos na Itália". Imaginação, à época, esclarece Barbosa (1999), remete à representação da figura humana concebida a partir de um modelo de beleza clássica inspirada na arte da Grécia e de Roma, portanto, submete-se a um cânone referência de representação da figura humana caracterizado pela simetria bilateral e sem as irregularidades próprias dos corpos humanos vivos. Por isso, o modelo vivo em nada se parecia com as figuras que surgiam no papel. (BARBOSA, 1999).

No caso da música, por exemplo, D. João VI delegou ao Padre José Maurício Nunes Garcia o mais alto posto de autoridade musical (MELO, 1947). Este compositor já trazia elementos explícitos do classicismo em suas composições, mas não representava 
os artistas franceses da missão artística, uma vez que era natural do Rio de Janeiro. Tal situação evidencia a complexidade de discutir o espaço do clássico na educação brasileira, dada a particularidade da nossa matriz sociocultural. Se na realidade europeia a aproximação ou distanciamento dos referenciais estéticos clássicos é resultado de um processo dialético, no Brasil, soma-se a distância da metrópole (ainda no fim do período colonial) que resulta em um deslocamento temporal que não apenas retarda a chegada de referenciais estéticos, mas os veste de personalidade própria, muitas vezes descaracterizando e re-caracterizando a matriz estética original.

O segundo elemento-chave da Missão Artística Francesa refere-se à aproximação com os clássicos que se dá obrigatoriamente pela educação, neste caso, na Escola Superior de Belas Artes. Ou seja, seria pelo processo educacional sistematizado que se difundiria o conhecimento dos clássicos no Brasil, afinal, com a vinda da corte para o que se tornaria temporariamente a capital do império português, a difusão desse conhecimento era condição essencial ao processo "civilizatório".

Enfim, por meio dessas reflexões, identifica-se o termo clássico significando um movimento ou período artístico, um estilo, uma linguagem artística, a exemplo do modelo greco-romano e às obras realizadas de acordo com as regras da perspectiva, com ênfase na composição organizada a partir de princípios como harmonia, simetria e equilíbrio, como forma de designar, grosso modo, a Arte Grega, séculos V e IV a.C., e do Renascimento, movimento que se originou na Itália, no século XIV, atingindo seu apogeu no século XVI (BENDALA, 1989).

De algum modo, a noção de clássico que ainda perpassa o processo ensino-aprendizagem do ensino da arte no Brasil é atravessada pela afirmação ou negação dos princípios formais importados pela Missão Francesa, que foram fartamente utilizados na configuração de uma biografia visual da nação, ao longo do século XIX.

Destaca-se ainda o fato de que a vinda de uma nova estética às terras brasileiras não se deu de forma simples, tampouco linear. Na verdade, havia uma forte presença da estética barroca que, por consequência de um isolamento sociocultural pôde adentrar o período histórico que já era marcado pelo neoclassicismo na Europa. O clássico, neste caso, é tendencialmente associado a negação do Barroco e do Romantismo.

No universo musical a análise desse processo de transição é mais complexa, uma vez que os registros musicais são o principal documento histórico que fundamenta a construção de uma historiografia da Educação Musical brasileira na sua transição do período colonial ao império. É necessário, ainda, destacar que a escrita musical é quase inteiramente relacionada à música canônica da cultura erudita dominante, excluindo-se a grande variedade de práticas musicais não ligadas à igreja ou ao ensino conservatorial de música. Dessa forma, pode-se supor que, mesmo após meio século da expulsão dos Jesuítas, o vasto referencial estético da música barroca (HOLLER, 2010) ainda estava amplamente presente no momento em que a corte portuguesa recém instalada almejava instaurar um novo modelo estético: o clássico encontraria um barroco tardio, mestiço e enraizado. 
As reflexões do parágrafo acima demonstram que a inserção de uma estética por meio da educação não significa, necessariamente, a anulação dos referenciais culturais anteriores. No caso do Brasil, embora o vigor do classicismo, representado pela releitura e imitação temática e compositiva dos gregos e romanos, pode-se afirmar que é característico do século XIX, a convivência harmoniosa entre o passado barroco, o neoclássico dos artistas franceses e o Romantismo. Talvez esse processo esteja na origem da dificuldade em encontrar o espaço dos referenciais estéticos clássicos no ensino da Arte dos séculos XX e XXI. Com a preocupação de afirmar nossa brasilidade e, ao mesmo tempo, alinhar-se à vanguarda mundial (europeia àquela época e global, atualmente), entende-se, por vezes, o clássico enquanto imposição, conflito ou retrocesso. Mas, como será desenvolvido a seguir, entende-se que há outras formas de abordar, e mesmo valorizar, as contribuições do clássico na formação artística.

\section{O lugar do clássico na escola e nas aulas de arte}

Tratando sobre o lugar do clássico na escola, em particular nas aulas de arte, tal empreitada implica, inicialmente, um exame dos critérios que permitem a uma obra de arte sobreviver "às condições que lhe deram origem" ou ainda: o que permite seu "contínuo reavivar-se", seu "escandir-se no tempo" (KOSIK, 1976, p. 124-130).

Em segundo lugar, passa pela identificação dos conteudos artísticos e culturais, que precisam ser transmitidos e assimilados dos diferentes campos da arte, sua organização e sequenciação; por fim, passa pela crítica ao modelo de organização dos saberes escolares próprio do sistema de ensino dividido em etapas bimetrais, semestrais ou anuais; pois, essa divisão, feita sem o devido cuidado com os diferentes graus de complexidade dos conceitos a serem apreendidos e sem relação com conceitos anteriores ou pré-requsitos, acaba levando a uma fragmentação dos saberes em partes desconexas (KLEIN, 2000).

Mesmo que se reconheça que todo traço cultural que se faz presente nos currículos escolares é sempre resultado de uma tradição seletiva da escola, conforme Forquin (1993), deve-se também entender que os estudantes têm o direito de conhecer as escolhas estéticas de um determinado grupo cultural. Embora, este grupo, em determinado momento, possa definir o que é passível de fazer parte e os porquês de fazer parte do currículo, a produção científica, artística, filosófica é produto do trabalho de todos os homens e mulheres, portanto, pertence a humanidade. A definição de clássico aproxima-se deste conceito, na medida em que sua classificação como tal não está apoiada apenas em suas características estéticas e formais, mas também na sua apropriação e valoração por um determinado grupo, em determinada época.

Duarte, neste sentido, ao pôr às claras a finalidade nuclear do sistema educacional público, ajuda-nos a pensar o acesso dos filhos e filhas da classe trabalhadora a mais rica produção científica, artística e filosofia, ou seja, aos clássicos, "posto que os filhos da classe dominante já têm esse acesso assegurado" (DUARTE, 2006, p. 615). Duarte joga luz sobre uma série de distorções, que há tempos dissemina-se, 
esclarecendo as consequências perversas desses argumentos, alguns externalizados até por intelectuais de esquerda. No que diz respeito aos fundamentos do ensino da arte, Duarte (2006) esclarece que a crítica mais comum é que a arte, geralmente denominada de erudita, pertence às classes abastadas e nada tem a acrescentar à classe trabalhadora. Para este autor é um equívoco afirmar "que a ciência e a arte burguesa são alheias à cultura da classe trabalhadora e produzem um alheamento em relação a essa cultura por parte daqueles que a vivem" (DUARTE, 2006, p. 615). Ele se opõe e esclarece que é um equívoco, "em primeiro lugar, porque o fato de boa parte da produção científica e artística terem sido apropriadas pela burguesia, transformando-se em propriedade privada e tendo seu sentido associado ao universo material e cultural burguês, não significa que os conhecimentos científicos e as obras artísticas sejam inerentemente burgueses. (DUARTE, 2006, p. 615).

Saviani esclarece que o desconhecimento do duplo e ambíguo sentido do termo erudição, por exemplo, pode resultar na mera oposição ao erudito ou ao clássico, sem a necessária compreensão de ambos. Por essa razão ele elucida que o termo erudição:

Por um lado, expressa um saber amplo e detalhado, sendo erudito alguém que domina os pormenores da ciência ou arte que cultiva. Por outro lado, reporta-se a um sentido depreciativo, significando uma multiplicidade de conhecimentos que não se articulam orgânica e criticamente. Por esse aspecto a erudição opõe-se à cultura, sendo entendida como um saber gratuito, descolado dos efetivos modos de pensar, agir e sentir que definem a cultura (SAVIANI, 2009, p. XVII).

Esse descuido em relação ao sentido e ao conteúdo dos termos, a exemplo do termo erudição, leva à compreensão do clássico como "saber gratuito" ou como "tradicional". À vista disso, fazendo frente a essas críticas, Saviani (2013, p. 19) esclarece: "O clássico não se confunde com o tradicional e também não se opõe, necessariamente, ao moderno e muito menos ao atual. $O$ clássico é aquilo que se firmou como fundamental, como essencial". Outro equívoco também esclarecido por Saviani refere-se a ideia de que a defesa do clássico é a negação do saber espontâneo. Ele aclara que a escola, por meio do trabalho educativo, enquanto atividade mediadora, realiza "a passagem do saber espontâneo ao saber sistematizado, da cultura popular à cultura erudita" e que essa passagem trata-se de

(...) um movimento dialético, isto é, a ação escolar permite que se acrescentem novas determinações que enriquecem as anteriores e estas, portanto, de forma alguma são excluídas. Assim, o acesso à cultura erudita possibilita a apropriação de novas formas por meio das se podem expressar os próprios conteúdos do saber popular. Cabe, pois, não perder de vista o caráter derivado da cultura erudita em relação a cultura popular, cuja primazia não é destronada. Sendo uma determinação que se acrescenta, a restrição a cultura erudita conferirá aqueles que dela se apropriam uma situação de privilé- 
gio, uma vez que o aspecto popular não lhes é estranho. A recíproca, porém, não é verdadeira: os membros da população marginalizados da cultura letrada tenderão a encará-la como uma potência estranha que os desarma e domina" (SAVIANI, 2013, p. 20).

Assim sendo, Saviani (2013) defende uma formação com ênfase no conhecimento dos clássicos, argumentando que uma maior familiarização com o conhecimento filosófico, por exemplo, garantirá maior erudição aos professores.

Duarte (2006), por sua vez, descontrói a crítica que se fundamenta na visão de que qualquer projeto educacional pautado explícita ou implicitamente na existência de uma cultura universal é um projeto conservador, autoritário e etnocêntrico. Duarte explica: esses críticos do clássico e da socialização de cultura universal argumentam, então, em favor do relativismo cultural como um dos pilares da educação em geral, inclusive da educação escolar.

De fato, concordando com Duarte (2006) e Saviani (2013), esses são alguns dos argumentos que mais nos impelem a defender o acesso aos clássicos para qualquer estudante brasileiro, independentemente de sua realidade social, cultural ou econômica. E as razões são as seguintes: em primeiro lugar porque, se o conhecimento dos clássicos é muitas vezes utilizado enquanto elemento de distinção social pelas classes mais favorecidas (BOURDIEU e DARBEL, 2003) é justamente sua ampla difusão, sua socialização, uma das formas de se romper a falsa ideia de que o acesso ao clássico é privilégio das classes abastadas e esse processo tem na Educação Básica, voltada à maioria das crianças e jovens brasileiros, e na formação inicial e continuada do professor seus espaços mais importantes. Em segundo lugar - rompendo com a visão capitalista de que um objeto só é nosso, segundo Marx (2010, p. 108), se é "imediatamente possuído, comido, bebido, trazido em nosso corpo, habitado por nós, etc. enfim, usado" -, possuir a cultura significa apropriar-se de seus sentidos. Partindo da ideia de que "o conhecimento não é um dado, é um ato, segundo Konder" (1966, p. 25), entende-se que possuir os clássicos significa conhecê-los, caminho para se produzir novos sentidos sobre os clássicos em diálogo com seus autores. Isso significa dizer que a própria definição do referencial estético clássico só é possível em diálogo com outros referenciais, indicando aproximações e distanciamentos históricos, incluindo-se os referenciais de forma e conteúdo, segundo Pareyson (1984, p. 57), compreendidos enquanto "humanidade e estilo".

É com base na afirmação acima que compreende-se a necessidade de oferecer a todos os alunos brasileiros um acesso amplo aos referenciais clássicos. Desta forma defende-se o direito de aprendizagem dos conhecimentos por que permitem ao aluno exercer o pleno exercício de autonomia estética e de escolha no mundo em que vivemos, pois a autonomia em relação às próprias escolhas estéticas dá-se por conhecimento e não por exclusão ou desconhecimento dos clássicos (ROMANELLI, 2014). 
Saviani (2013), em relação as marcas indeléveis do clássico, faz referência à aspectos que "permanecem", que "se firmam", argumentando que firmar-se decorre de um processo de "depuração". Mas, ao postular que há uma validade dos conteúdos que extrapola o momento de sua elaboração, outra problemática se põe: como chegar ao núcleo de validade dos clássicos, ao que lhe imprime temporalidade? Pareyson (1984) responde, exatamente por serem filhos de seu tempo, os clássicos e as obras de arte em geral vivem temporalmente além do tempo e conseguem escandir-se no tempo.

As reflexões desses autores, enfim, muito contribuem para o debate sobre os clássicos na educação em arte, sobretudo para se desfazer visões equivocadas vigentes. Reconhecer os efeitos dessas distorções é fundamental, antes de mais nada, para uma sólida formação tanto dos alunos quanto dos professores.

\section{Considerações finais: quando os clássicos tornam-se alegrias ambiciosas?}

Estaria Snyders (1988) certo quando buscava encontrar na escola o que ela pode oferecer de particular, de insubstituível? Sim, indiscutivelmente certo, sobretudo em seus argumentos sobre a escola poder tudo apostar na satisfação da cultura elaborada, sem negar que a grandeza e as alegrias oriundas do acesso aos clássicos demandam seriedade, disciplina e esforços intensos.

Na escola de Snyders o contato com os clássicos, além de direito de todo cidadão e dever do estado, pode ser fonte de prazer, de alegria? Na escola de Snyders sim. E na nossa escola também é fonte de satisfação o acesso as grandes produções artísticas, filosóficas e científicas, aos poemas de amor. Mas a satisfação da cultura, relembrando Saviani (2009), não significa renunciar aos saberes espontâneos, as alegrias cotidianas, porém compreender que uma boa dose cultura é condição indispensável para a superação do senso comum na direção da consciência filosófica.

Por isso é fundamental uma formação dos professores aproximando-os também dos clássicos que eles ensinam, trata-se de ter acesso ao que existe de grandioso, de apelo à grandeza da vida. Trata-se de transformar a escola em lugar da satisfação do conhecimento, trata-se de afirmar: a cultura, a arte, os clássicos dão satisfação. Tem que ter poesia na escola. 


\section{Referências}

BARBOSA, João Alexandre. Introdução. In: GUINSBURG, Jacó (Org.). O classicismo. São Paulo: Perspectiva, 1997.

BARBOSA, Ana Mae. Arte-educação no Brasil. 3. ed. São Paulo, SP: Perspectiva, 1999.

BENDALA, Manuel. Saber ver a arte grega. São Paulo: Martins Fontes, 1989. (Coleção Saber ver a Arte).

BOURDIEU, Pierre; DARBEL, Alain. L'amour de l'art. Paris: Les Éditions de Minuit, 2003.

CALVINO, Ítalo. Por que ler os clássicos? São Paulo: Companhia da Letras, 2007.

CARVALHO, José Murilo. A formação das almas: o imaginário da República no Brasil. São Paulo: Companhia das Letras, 1990.

CSIKSZENTMIHALYI, Mihail. Creativity: Flow and the Psychology of discovery and invention (1st ed.). New York: HarperPerennial, 1997.

DUARTE, Newton. A contradição entre universalidade da cultura humana e o esvaziamento das relações sociais: por uma educação que supere a falsa escolha entre etnocentrismo ou relativismo cultural. In: Educação e Pesquisa. São Paulo, v. 32, n. 3, sept/dec. 2006. Disponível em: http://www.scielo.br. Acesso em: 10 jan. 2021.

FORQUIN, Jean-Claude. Escola e Cultura. Porto Alegre: Artes Médicas, 1993.

HOLLER, Marcos. Os jesuítas e a música no Brasil colonial. Campinas: Ed. da UNICAMP, 2010.

KLEIN, Ligia R. Proposta político-pedagógica para o Ensino Fundamental:

Cadernos da Escola Guaicuru. Mato Grosso do Sul: Secretaria de Estado de Educação de Mato Grosso do Sul, 2000.

KLEIN, Ligia R. Alfabetização: quem tem medo de ensinar? 5. ed. São Paulo: Cortez; Campo Grande: Editora Universidade Federal do Mato Grosso do Sul, 2008.

KONDER, Leandro. Os marxistas e a arte: breve estudo histórico-crítico de algumas tendências da estética marxista. Rio de janeiro, RJ: Civilização Brasileira, 1966.

KOSIK, Karel. Dialética do concreto. Rio de Janeiro: Paz e Terra, 1976. 
LEMINSKI, Paulo. Paulo Leminski: ensaios e anseios crípticos. Curitiba, PR: Inventa, 2014. (Coleção Gazeta do Povo: Literatura paranaense).

MALERBA, Jurandir. A corte no exílio: civilização e poder no Brasil às vésperas da Independência (1808 a 1821). São Paulo: Companhia das Letras, 2000.

MARX Karl., ENGELS, Friedrich. A ideologia alemã. 9. ed. São Paulo: Hucitec, 1993.

MARX, Karl. Manuscritos econômico-filosóficos. São Paulo: Boitempo, 2010.

MELO, Guilherme. A música no Brasil. Rio de Janeiro: Imprensa Nacional, 1947.

NAVES, Rodrigo. A forma difícil: ensaios sobre arte brasileira. 2.ed. São Paulo: Ática, 1997.

PAREYSON, Luigi. Os problemas da estética. São Paulo, SP: Martins Fontes, 1984.

PECHMAN, Robert Moses. Cidades estreitamente vigiadas. Rio de Janeiro: Casa da Palavra, 2002.

ROMANELLI, Guilherme. Antes de falar as crianças cantam! Considerações sobre o ensino de música na educação infantil. Revista Teoria e Prática da Educação, v. 17, n.3, 61-71, 2014

SAVIANI, Dermeval. Pedagogia histórico-crítica: primeiras aproximações. 11. ed. Campinas, SP: Editores Associados, 2013.

SAVIANI, Dermeval. Educação: do senso comum à consciência filosófica. São Paulo: Autores Associados, 2009.

\section{SCHLICHTA, Consuelo A. B. D. A pintura histórica e a elaboração de uma} certidão visual para a nação no século XIX. Curitiba, 2006. Tese (Doutorado) - Universidade Federal do Paraná, Setor de Ciências Humanas, Letras e Artes, Programa de Pós-Graduação do Departamento de História da UFPR.

SNYDERS, Georges. A alegria na escola. São Paulo, SP: Editora Manolo, 1988.

Submetido em 16/09/2021.

Aprovado em 22/10/2021. 